\title{
EFEITOS DE RETARDADORES DE CRESCIMENTO NA FRUTIFICAÇÃO DA VIDEIRA 'NIAGARA ROSADA'
}

\author{
Paulo R. C. Castro \\ Eduardo C. Ferraz ** \\ Marcel Awad
}

\section{RESUMO}

\begin{abstract}
Estudou-se a influência da aplicação por imersão, de retardadores de crescimento (CCC e SADH), 5 dias antes do florescimento, nas características morfológicas da panícula da videira Vitis (labrusca $x$ vinifera) 'Niagara Rosada'.

Neste ensaio verificou-se que as concentrações de CCC aplicadas em pré-florescimento, não afetaram favoravelmente a morfologia das panículas da cultivar estudada, nas condições do ensaio.

SADH na dosagem de $1000 \mathrm{ppm}$ provocou, na primeira colheita, aumento no peso e comprimento da panícula, no peso das bagas, e no comprimento da ráquis, proporcionando a formação desejada de uma panícula mais alongada, nas condições estudadas. Aplicação de SADH na concentração de $250 \mathrm{ppm}$ em pré-florescimento, promo. veu aumento no peso e comprimento da panícula, número e peso das bagas, além do inconveniente de elevar o número de sementes.
\end{abstract}

\section{INTRODUÇAOO}

A Vitis (labrusca $x$ vinifera) 'Niagara Rosada' é a uva de mesa mais extensamente cultivada nas condições brasileiras. Considera-se a 'Niagara Rosada' de grande aceitação no mercado, sendo seu sabor foxado, para a maioria consumidora de uva fresca no Brasil, a característica mais apreciável da cultivar, além da coloração rosada (SOUSA, 1969). As panículas mastram-se bastante variáveis; apresentando-se de tamanho médio para grandes, com forma cilíndrico-cônicas e compactas em plantas novas ou em condições de plena fertilidade. As bagas apresentam-se com tamanho

- Entregue para publicação em 13/12/1974.

* Departamento de Botanica. E. S. A. \&Luiz de Queiroz» - U. S. P.

*** Departamento de Biologia. Faculdade de Filosofia, Ciências e Letras de Ribeirăo Preto U. S. P. 
médio, globosas, de textura fundente e sabor foxado, típico das castas americanas (PEREIRA, 1972).

NITSCH et al. (1960) efetuaram um estudo comparativo do desenvolvimento da baga da videira cultivar 'Concord' e de sua presumível mutante 'Concord Seedless'. Os autores determinaram quatro fases distintas no crescimento da baga de 'Concord'; sendo que no período zero observaram crescimento limitado e baixo conteúdo de substância de crescimento; no primeiro período notaram rápido crescimento e alta concentração de substância de crescimento; no segundo período tiveram uma diminuição lenta e evidente no crescimento e uma queda repentina no nível da substância de crescimento; no terceiro período uma retomada de aumento ativo no peso fresco e peso seco, sem ocorrer aumento em substância de crescimento. Na cultivar 'Concord Seedless', o crescimento do nucelo e a produção de substâncias de crescimento aumentam mais rapidamente durante o período zero do que em 'Concord', mas a degeneração do endosperma e a redução no nível de substância de crescimento continua durante a metade do primeiro período. 0 segundo período é imperceptível. A produção inicial de substância de crescimento nas videiras estudadas pode ser melhor associada com o nucleo do que com o desenvolvimento do endosperma.

Sabe-se que a aplicação de reguladores de crescimento tem contribuido efetivamente na cultura da videira, promovendo em diversas cultivares melhor produção, pelo aumento do peso das panículas e das bagas. Tem-se verificado ainda melhoria na qualidade das uvas, através do aumento no tamanho das panículas e das bagas, da obtenção de panículas medianamente soltas, do engrossamento da ráquis e ráquilas, e da obtenção de bagas sem sementes; além disso a diminuição do ciclo de maturação da videira tem possibilitado adiantamento da época de colheita.

KOCKEMANN (1934) descobriu compostos inibidores em sementes, sendo que AUDUS (1947) verificou que a cumarina, assim como outras lactonas que limitam as taxas de crescimento e germinação, ocorre em raízes. HEMBERG (1949.a) encontrou quantidades apreciáveis de inibidores em gemas dormentes de batata e em freixo (HEMBERG, 1949.b). Extratos de inúmeros tecidos vegetais mostraram possuir substâncias com propriedades inibitórias; sendo que o ácido abscísico (ABA) parece ser um dos principais compostos envolvidos (BENNET-CLARK \& KEFFORD, 1953; MILLBORROW, 1967).

Compostos orgânicos sintéticos mostraram capacidade de retardar a elongação do ramo, intensificar a coloração verde das folhas e afetar indiretamente o florescimento sem causar deformações na planta; sendo considerados retardadores de crescimento vegetal (WEAVER, 1972). Os retardadores de crescimento poderiam atuar, inibindo a produção de outro hormônio, estimulando a quebra de outro hormônio, interferindo na ação de um hormônio promotor de crescimento ou agindo independentemente dos promotores de crescimento. 
Os primeiros retardadores de crescimento vegetal descobertos foram os nicotiniuns (MITCHELL, WIRWILLE \& WEIL, 1949) que reduziam a elongação da haste de plantas de feijoeiro. WIRWILLE \& MITCHELL (1950) demonstraram que uma série de carbamatos de amônio quaterná. rios retardam o crescimento de feijoeiro; sendo que o amônio (5-hidroxicarvacril) trimetil cloreto piperidina carboxilato (Amo - 1618) mostrou ser o mais ativo do grupo. TOLBERT (1960) relatou a existência de outra série de compostos amoniacais quaternários; sendo que o mais ativo destes foi o denominado cloreto de (2-cloroetil) trimetilamônio (CCC) que mostrou-se capaz de retardar o crescimento de maior número de espécies que os demais compostos já conhecidos. RIDDELL et al. (1962) verificaram que o ácido succinâmico atua como um retardador de crescimento em hortaliças, batata, videira e plantas ornamentais, sendo que o composto denominado SADH (ácido succinâmico-2, 2-dimetilhidrazida) retarda o crescimento de muitas espécies.

O CCC possue uma estrutura quaternária e é um análogo da colina. Os sais brometo e cloreto são ativos e o catiônio trimetilamônio quaternário é necessário para a atividade. SADH pertence ao grupo dos ácidos succínicos, sendo um ácido livre, ionizável, contendo um sistema C-C-N-N.

Retardadores de crescimento vegetal como o $\mathrm{CCC}$ e o SADH, retardam a elongação de ramos evitando a divisão celular no meristema sub-apical, normalmente sem promover efeito similar no meristema apical (SACHS et al., 1960).

0 mecanismo de ação dos retardadores de crescimento é ainda muito pouco conhecido. Como o efeito destes compostos sobre as plantas é oposto ao das giberelinas, parece lógico acreditar que os retardadores atuam como antigiberelinas. Demonstrou-se que esta hipótese pode ser verdadeira com CCC e o fungo Fusarium moniliforme (KENDE, NINNEMANN \& LANG, 1963) e CCC em plantas superiores (HARADA \& LANG, 1965). Nestes experimentos a síntese de giberelina foi bloqueada, mas a giberelina já presente nos tecidos não foi afetada. O mecanismo de ação do SADH pode ser baseado na hidrólise do composto para UDMH (dimetilhidrazina assimétrica), que posteriormente inibe a diamina oxidase da conversão de triptamina para IAA (REED, MOORE \& ANDERSON, 1965). Entretanto, RYUGO \& SACHS (1969) concluiram de seus estudos que a metade UDMH não é a porção ativa do $\mathrm{SADH}$, e que o efeito primário do $\mathrm{SADH}$ é para inibir a síntese do IAA.

COOMBE (1965) verificou que a aplicação do cloreto de (2-cloretil) trimetilamônio antes da antese, na cultivar 'Muscat of Alexandria' promoveu aumento na fixação das bagas por elevação no número de bagas com sementes por panícula; além de aumento no peso da panícula.

A aplicação de SADH aumenta a fixação dos frutos das cultivares 'Himrod' e 'Concord' (TUKEY \& FLEMING, 1967). Concentração de 2000 ppm de SADH aplicada em 'Himrod', antes da antese, resulta num au- 
mento de $100 \%$ na fixação. 0 tratamento não reduz o tamanho das bagas, mas promove alguma inibição no crescimento vegetativo. Aplicação de SADH nas concentrações de 500 e 1000 ppm em 'Concord', antes ou durante o florescimento, aumenta a fixação de frutos e a colheita (TUKEY \& FLEMING, 1968).

TUKEY \& FLEMING (1970) observaram redução nas dimensões das bagas, porém aumentos na colheita, pela aplicação de SADH dois anos consecutivos; sendo que consideraram que os aumentos na colheita ocorreram como resultado de uma pobre fixação natural das bagas. 0 número médio de bagas nas panículas tratadas com SADH nas concentrações de 0, 500, 750 e $1000 \mathrm{ppm}$ foram $44,0,57,0,58,4$ e 62,1 , respectivamente.

EL-ZEFTAWI \& WESTE (1970) relataram que a aplicação de ácido giberélico na concentração de $1 \mathrm{ppm}$ mais CCC na dosagem de $100 \mathrm{ppm}$ em videira, produz colheitas mais altas que as obtidas pela aplicação da mistura de ácido giberélico e 4-CPA. O CCC deve aumentar a fixação, enquanto o ácido giberélico mantém o tamanho das bagas.

BARRITT (1970) observou que a aplicação de SADH nas dosagens de 250 a $2000 \mathrm{ppm}$ sobre as cultivares 'Himrod', 'N.Y. 21572' e 'N.Y. 21576', não aumentou o número de bagas por panícula, ou o peso da panícula; sendo que mostrou uma tendência em reduzir o peso médio de baga e os sólidos solúveis totais. Este mesmo autor verificou que o $\mathrm{CCC}$ nas concentrações de 500 a $1500 \mathrm{ppm}$, aplicado em pré-florescimento nas cultivares 'Himrod', 'N.Y. 21572' e 'N.Y.21576', promove aumento no número de bagas por panícula e no peso da panícula; sendo que o peso médio da baga e os sólidos solúveis totais permanecem inalterados.

PEREIRA \& YOSHIDA (1973) observaram que aplicação de CCC nas dosagens de 0,075, 0,150 e 0,300\% sobre a cultivar 'IAC 21-14' em pré-florescimento, promove significativo aumento no número de bagas por panícula, o que pode ser favorável nesta cultivar que apresenta panículas excessivamente soltas, desde que se consiga uma frutificação mais perfeita.

\section{MATERIAIS E METODOS}

Utilizaram-se videiras da cultivar 'Niagara Rosada' (Vitis labrusca L. $x$ Vitis vinifera L.) enxertadas sobre 'Riparia do Traviú' (Riparia $x$ Rupestris 'Cordifolia 106-8') com idade de 20 anos e produções médias anuais acima de $2 \mathrm{~kg} / \mathrm{m}^{2}$. Essas videiras, constituindo um conjunto recebendo tratos culturais cuidadosos, estavam localizadas em leve encosta, dispostas em linhas perpendiculares à declividade do terreno, em Louveira, S.P. Apresentavam espaçamento de $2 \times 1$ metro, sendo conduzidas no sistema de espaldeira de três fios com poda invernal em cordão esporonado. Encontravam-se em um solo que, dentre as unidades mapeadas pela Comissão de Solos em São Paulo, enquadra-se na Podzólico Vermelho Amarelo orto, correspondendo ao subgrupo "Typic Paleudult" na classificação 
proposta pelo "Soil Survey Staff" (VALADARES, LEPSCH \& KUPPER, 1971).

Dentre os retardadores de crescimento empregou-se o produto designado comercialmente por "Cycocel-50" da American Cyanamid Co. (Wayne, NJ.), fonte do cloreto de (2-cloroetil) trimetilamônio ou cloreto de cloro colina (CCC). Utilizou-se também "Alar-85", um produto comercial da UniRoyal Chemical Inc. (Naugatuck, Conn.), como fonte do ácido succinâmico-2, 2-dimetilhidrazina ( $\mathrm{SADH})$.

Todos os tratamentos com os reguladores de crescimento foram efetuados através de uma única imersão das panículas (FONT QUER, 1970) na solução contida em recipiente plastificado que era inutilizado após a aplicação. As soluções adicionou-se o espalhante adesivo "Novapal" da Bayer da Alemanha, na dosagem de $0,1 \%$. Os tratamentos foram aplicados sob condições meteorológicas favoráveis, não tendo ocorrido precipitação 48 horas antes ou após as aplicações. Nas videiras testemunha as panículas tratadas foram imersas em água pura com o agente surfactante. Trataram-se quatro panículas uniformes por planta, previamente marcadas com fita colorida de polietileno.

0 ensaio foi delineado em blocos casualizados (PIMENTEL GOMES, 1963). Realizaram-se 14 tratamentos, sendo distribuidos de forma casual em cada um dos quatro blocos cujas parcelas (representadas por uma planta) para maior homogeneidade, estavam dispostas em linha. Foi de 56 o número de plantas utilizadas no ensaio. Efetuaram-se as análises de variância de acordo com o esquema:

Causa de Variação

G.L.

Blocos

Tratamentos

Resíduo

Procedeu-se a comparação de médias pelo Teste de Tukey, calculando-se a diferença mínima significativa (D.M.S.) ao nível de 5 e $1 \%$ de probabilidade.

Efetuaram-se as colheitas das panículas em duas épocas distintas: a primeira aproximadamente na metade do período do florescimento à maturação das bagas e a segunda por ocasião da colheita final, com a maturação completa das bagas. Nestas colheitas retirou-se uma panícula marcada por planta e colocou-se etiqueta de identificação; sendo que as panículas, cuidadosamente acondicionadas em sacos de polietileno, foram 
levadas para uma câmara frigorífica a $5^{\circ} \mathrm{C}$, onde permaneceram por uma semana, até a avaliação dos dados considerados.

0 peso da panícula e das bagas determinou-se com precisão de 0,1 grama em uma balança Mettler P1200N. As medidas de comprimento da ráquis e largura da panícula e do engaço (ráquis + cachos sem bagas) foram obtidas com aproximação de 0,1 centímetro; sendo que o comprimento e largura das bagas, o diâmetro na porção mediana da ráquis e da ráquila (FERRI, MENEZES \& SCANAVACCA, 1969), e o comprimento da ráquila foram tomados com 0,01 centímetro de precisão em um paquímetro Hélios.

Quanto às análises do suco, verificamos em amostragens de todos os tratamentos, a dosagem dos açúcares $(\mathrm{g} / 100 \mathrm{ml})$ através de um refratômetro manual para Brix Bausch \& Lomb com 0,1 grau de precisão. A acidez total foi avaliada pelo método proposto pelo Ministério da Agricultura, sendo expressa em $\mathrm{ml}$ de hidróxido de sódio normal por $100 \mathrm{ml}$ do suco. Conhecendo-se o teor de açúcares e a acidez total, calculou-se o Indice de Maturação (açúcares/acidez total). Determinou-se ainda o teor de açúcares redutores $(\mathrm{g} / 100 \mathrm{ml})$ pelo método de Eynon-Lane (BROWNE \& ZERBAN, 1941; TOLEDO, 1960).

Videiras semelhantes em vigor foram selecionadas para tratamentos, em cada linha constituinte do bloco. Os tratamentos foram aplicados em videiras sorteadas dentro de cada um dos quatro blocos.

As aplicações dos reguladores de crescimento foram realizadas cinco dias antes do florescimento, em 9 de outubro de 1971. O florescimento máximo deu-se em 14 de outubro, neste ano.

Além do tratamento controle, aplicou-se cloreto de (2-cloroetil) trimetilamônio (CCC) nas concentrações de 50, 100, 250, 500, 1000 e 2000 ppm. Efetuou-se ainda aplicação de SADH (ácido succinâmico-2, 2-dimethilhidrazida) nas concentrações de 50, 100, 250, 500, 1000 e 2000 ppm; sendo que realizou-se ainda um tratamento com CCC $500 \mathrm{ppm}+\mathrm{SADH}$ $500 \mathrm{ppm}$.

Em 25 de novembro de 1971 retirou-se a amostragem de uma panicula tratada por planta, nas 56 videiras. As panículas foram acondicionadas e levadas para a câmara frigorífica. Determinou-se, em cada panícula, o peso da panícula, comprimento da panícula, largura da panícula, número de bagas, peso das bagas, comprimento médio das bagas, largura média das bagas, relação comprimento médio/largura média das bagas. Verificou-se também o comprimento da ráquis, largura do engaço, diâmetro da ráquis, comprimento da ráquila e diâmetro da ráquila.

$\mathrm{Na}$ colheita final, em 5 de janeiro de 1972, retirou-se nova amostragem de uma panícula tratada por planta; sendo que procedeu-se da mesma forma e efetuaram-se as mesmas determinações da primeira colheita, além da contagem das bagas e das sementes. Coletaram-se ainda, 
amostras de todos os tratamentos para determinação dos açúcares, acidez total, fndice de Maturação e açúcares redutores.

\section{RESULTADOS E DISCUSSAO}

Quadro 1 - Efeitos da aplicação de reguladores de crescimento em $9 / 10 / 71$, nas frutificações das videiras 'Niagara Rosada' coletadas em 25/11/71 (valores obtidos pelo Teste $F$ para tratamentos e coeficientes de variação em porcentagem).

\begin{tabular}{l|l|r}
\hline \multicolumn{1}{c|}{ Parâmetro } & \multicolumn{1}{c|}{ F } & C.V. (\%) \\
\hline Peso da panícula & $3,3495^{* *}$ & 25,93 \\
Comprimento da panícula & $2,2684^{*}$ & 13,36 \\
Largura da panícula & 1,4235 & 13,46 \\
Peso das bagas & $3,2505^{* *}$ & 26,44 \\
Comprimento médio (C.M.) das bagas & $3,9264^{* *}$ & 3,78 \\
Largura média (L.M.) das bagas & $4,8837^{* *}$ & 3,51 \\
Relação C.M./L.M. das bagas & $1,1680^{*}$ & 1,66 \\
Comprimento da ráquis & $2,6599^{* *}$ & 14,27 \\
Largura do engaço & 0,8651 & 23,57 \\
Diâmetro da ráquis & $2,0637^{*}$ & 9,03 \\
Comprimento da ráquila & 1,7455 & 9,86 \\
Diâmetro da ráquila & 1,6770 & 8,97 \\
\hline
\end{tabular}

(**) Significativo ao nível de $1 \%$

(*) Significativo ao nível de $5 \%$ 
Quadro 2 - Relação dos tratamentos efetuados no experimento e respectivas representações das médias.

TRATAMENTOS

Representações das médias

Testemunha

$\overline{\mathrm{T}}$

CCC 50 ppm

$\overline{\mathrm{CC}} 50$

CCC 100 ppm

$\overline{\mathrm{CC}} 100$

CCC 250 ppm

$\overline{\mathrm{CC}} 250$

CCC $500 \mathrm{ppm}$

$\overline{\mathrm{CC}} 500$

CCC 1000 ppm

$\overline{\mathrm{CC}} 1000$

CCC 2000 ppm

$\overline{\mathrm{CC}} 2000$

SADH $50 \mathrm{ppm}$

$\overline{\mathrm{SA}} 50$

SADH 100 ppm

$\overline{\mathrm{SA}} 100$

SADH 250 ppm

$\overline{\mathrm{SA}} 250$

SADH 500 ppm

$\overline{\mathrm{SA}} 500$

SADH $1000 \mathrm{ppm}$

$\overline{\mathrm{SA}} 1000$

SADH $2000 \mathrm{ppm}$

$\overline{\mathrm{SA}} 2000$

CCC $500 \mathrm{ppm}+\mathrm{SADH} 500 \mathrm{ppm}$

$\overline{\mathrm{CC}} 500+\overline{\mathrm{SA}} 500$ 
Ouadro 3 - Efeitos de aplicaçäo de reguladores de crescimento em 9/10/71 nas frutificações das videiras Niagara Rosada' coletadas em 25/11/71 (valores dos parâmetros obtidos pela média de quatro panículas a D.M.S. determinadas pelo Teste de Tukey).

\begin{tabular}{|c|c|c|c|c|c|}
\hline \multirow{2}{*}{ Tratamentos } & \multicolumn{5}{|c|}{ Médias } \\
\hline & $\begin{array}{l}\text { Peso da } \\
\text { panfcula } \\
\text { (a) }\end{array}$ & $\begin{array}{c}\text { Comprimento } \\
\text { da panf(cula } \\
\text { (cm) }\end{array}$ & $\begin{array}{l}\text { Largura da } \\
\text { panfícula } \\
\text { (cm) }\end{array}$ & $\begin{array}{c}\text { Poso das } \\
\text { begas } \\
(g)\end{array}$ & $\begin{array}{l}\text { Comprimonto } \\
\text { midio das bagas } \\
\text { (cm) }\end{array}$ \\
\hline$\overline{\mathbf{T}}$ & 46,44999 & 8,82500 & 6,05000 & 44,77499 & 1,59249 \\
\hline$\overline{\mathrm{CC}} 50$ & 49,37500 & 10,35000 & 5,94999 & 47,67499 & 1,56999 \\
\hline$\overline{C C} 100$ & 83,60000 & 11,35000 & 6,32499 & 80,72500 & 1,64249 \\
\hline$\overline{C C} 250$ & 63,79999 & 9,59999 & 6,92999 & 61,67499 & 1,59499 \\
\hline$\overline{C C} 500$ & 67,02500 & 10,87500 & 6,44999 & 64,37500 & 1,56250 \\
\hline$\overline{\mathrm{CC}} 1000$ & 63,79998 & 10,45000 & 6,64999 & 61,30000 & 1,58750 \\
\hline$\overline{\mathrm{CC}} 2000$ & 48,59999 & 10,82500 & 6,22499 & 46,40000 & 1,52250 \\
\hline$\overline{S A} 50$ & 66,55000 & 10,62500 & 6,79999 & 64,05000 & 1,69249 \\
\hline$\overline{S A} 100$ & 62,99999 & 9,85000 & 7,02499 & 60,65000 & 1,70749 \\
\hline$\overline{S A} 250$ & 55,34999 & 10,22550 & 6,72500 & 52,82499 & 1,64499 \\
\hline$\overline{S A} 500$ & 77,00000 & 11,75000 & 6,69999 & 73,22500 & 1,64499 \\
\hline$\overline{S A} 1000$ & 88,75000 & 12,57499 & 7,27499 & 85,30000 & 1,60749 \\
\hline$\overline{S A} 2000$ & 69,35000 & 10,72500 & 6,34999 & 66,30000 & 1,59749 \\
\hline$\overline{C C} 500+\overline{S A} 500$ & 34,75000 & 8,64999 & 5,22500 & 33,00000 & 1,48749 \\
\hline D.M.S. 5\% & 41,12249 & 3,54358 & 2,20561 & 40,24629 & 0,15378 \\
\hline D.M.S. 1\% & 48,11169 & 4,14584 & 2,58047 & 47,08657 & 0,17992 \\
\hline
\end{tabular}




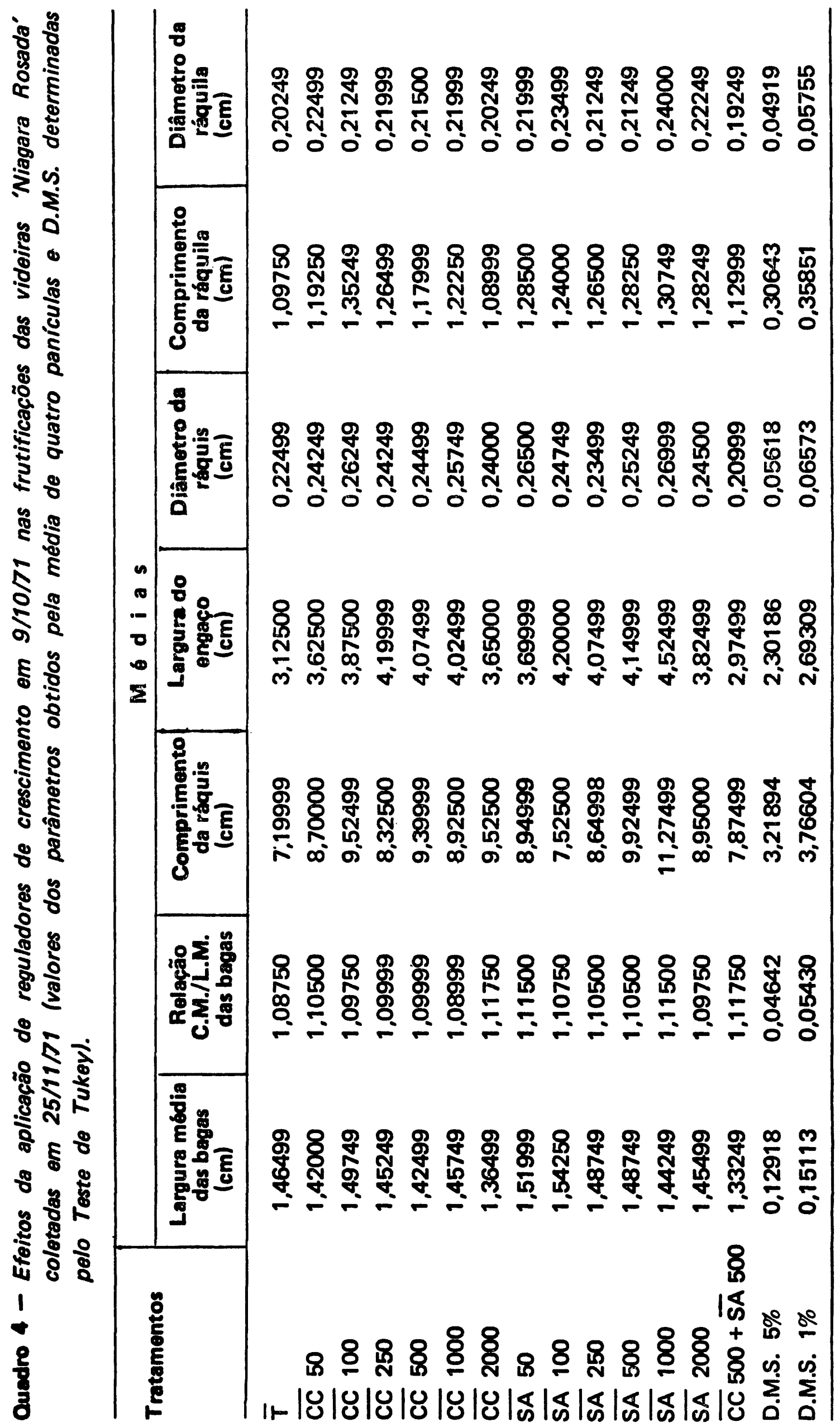


Quadro 5 - Efeitos da aplicação de reguladores de crescimento em $9 / 10 / 71$, nas frutificações das videiras 'Niagara Rosada' coletadas em 5/1/72 (valores obtidos pelo Teste $F$ para tratamentos e coeficientes de variação em porcentagem).

\begin{tabular}{lc|c}
\hline \multicolumn{1}{c|}{ Parâmetro } & $\mathrm{F}$ & $\mathrm{C} . \mathrm{V} .(\%)$ \\
\hline Peso da panícula & $4,8408^{* *}$ & 23,70 \\
Comprimento da panícula & $4,0758^{* *}$ & 10,14 \\
Largura da panícula & $2,8143^{* *}$ & 11,80 \\
Número de bagas & $3,2745^{* *}$ & 11,90 \\
Peso das bagas & $4,9000^{* *}$ & 23,65 \\
Comprimento médio (C.M.) das bagas & $3,3598 * *$ & 4,43 \\
Largura média (L.M.) das bagas & $3,8009^{* *}$ & 3,71 \\
Relação C.M./L.M. das bagas & $2,2891 *$ & 1,48 \\
Número de sementes & $3,5573 * *$ & 14,38 \\
Comprimento da ráquis & $2,9517 * *$ & 12,36 \\
Largura do engaço & 1,3879 & 22,79 \\
Diâmetro da ráquis & 1,2586 & 12,28 \\
Comprimento da ráquila & 1,6231 & 15,18 \\
Diâmetro da ráquila & 1,7380 & 13,33 \\
\hline
\end{tabular}

(**) Significativo ao nível de $1 \%$

(*) Significativo ao nível de 5\% 


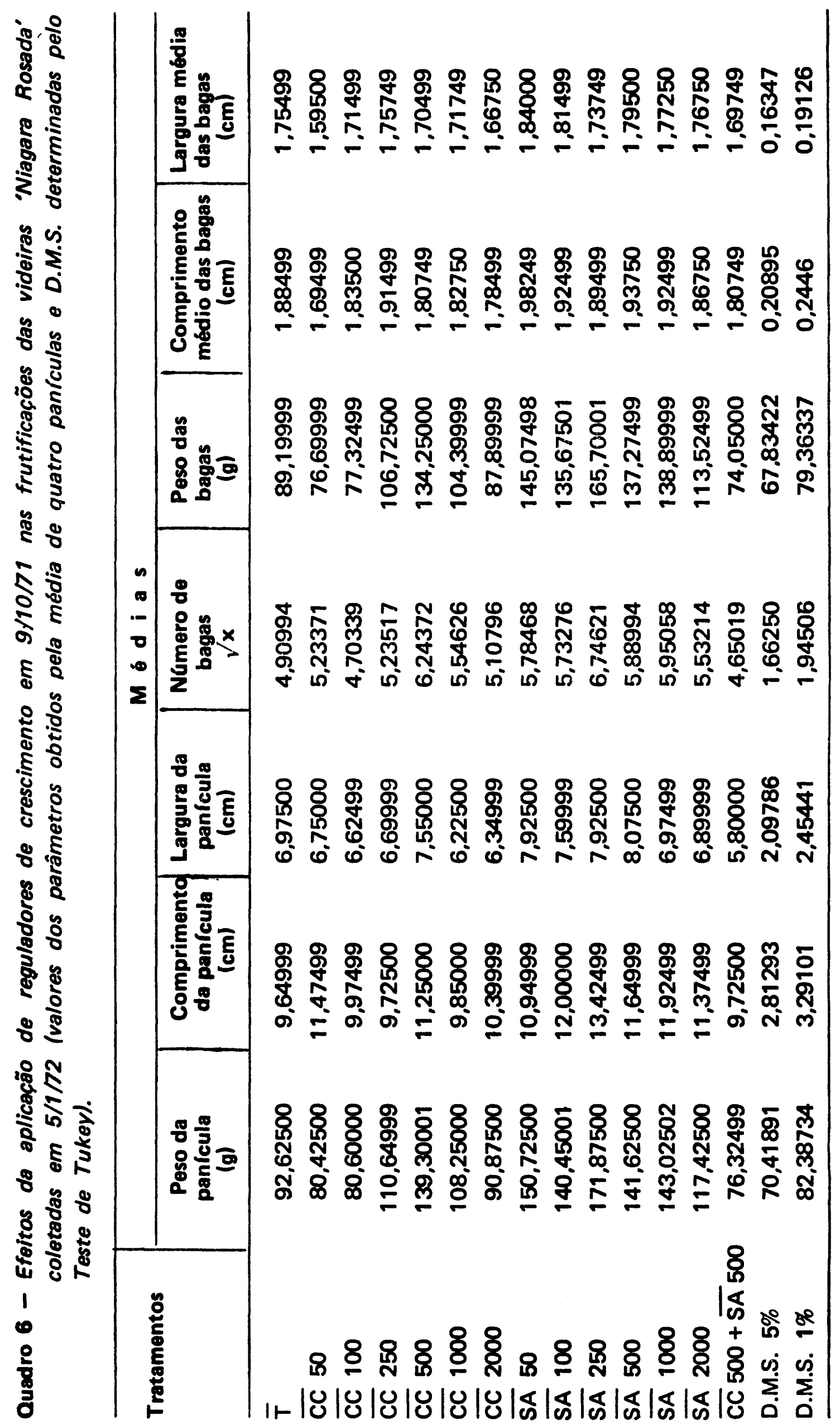




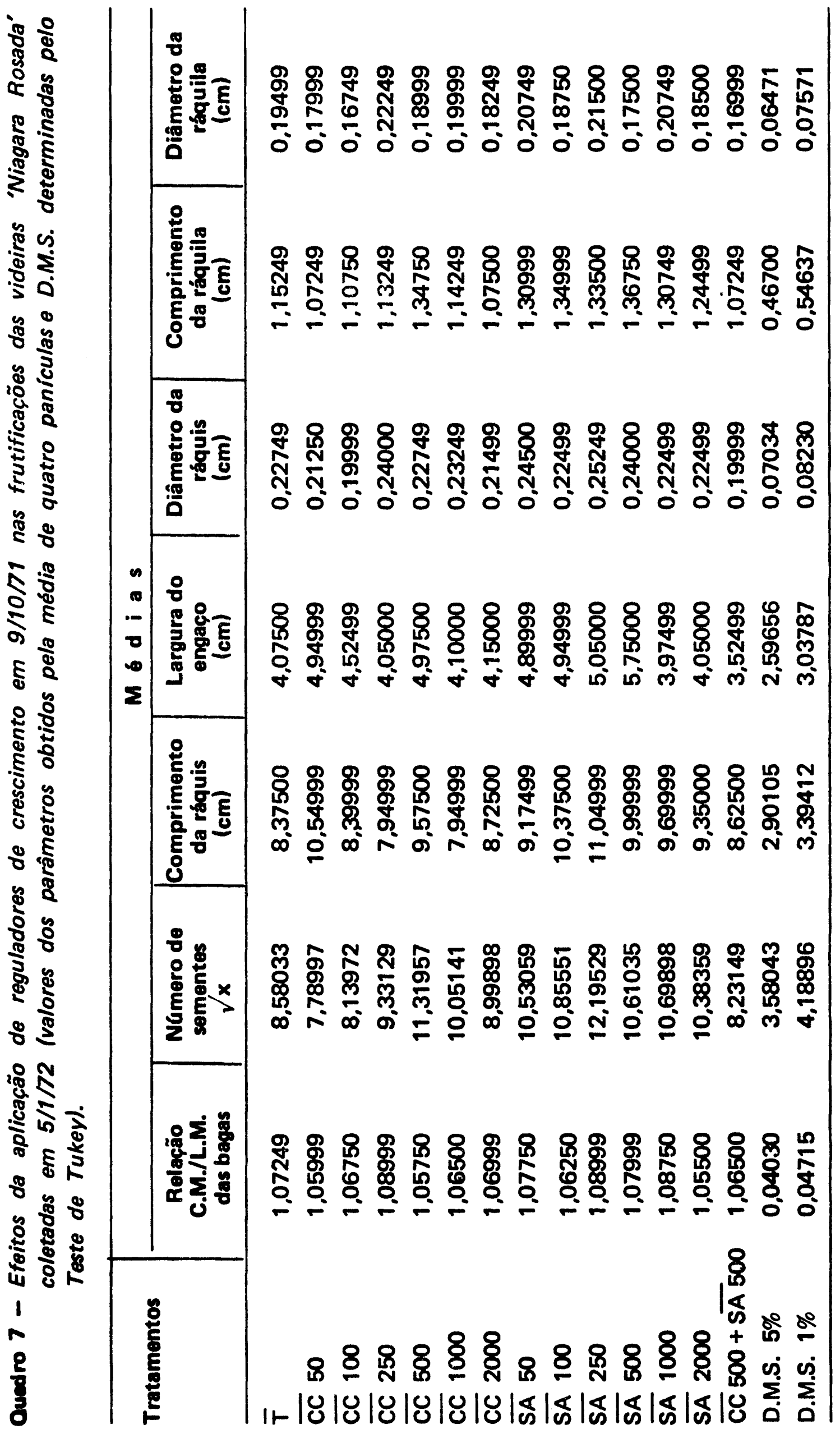


Quadro 8 - Efeitos da aplicação de reguladores de crescimento em $9 / 10 / 71$, na dosagem de açúcares $(\mathrm{g} / 100 \mathrm{ml})$, acidez total $(\mathrm{NaOH} 1 \mathrm{~N} / 100 \mathrm{ml})$, Índice de Maturação e açúcares redutores $(\mathrm{g} / 100 \mathrm{ml})$, em amostragens das frutificações das videiras 'Niagara Rosada' coletadas em 5/1/72.

\begin{tabular}{lcc|c|c}
\hline Tratamentos & Açúcares & $\begin{array}{c}\text { Acidez } \\
\text { Total }\end{array}$ & $\begin{array}{c}\text { Indice de } \\
\text { Maturação }\end{array}$ & $\begin{array}{c}\text { Açúcares } \\
\text { Redutores }\end{array}$ \\
\hline T & 12,3 & 13,5 & 0,911 & 10,85 \\
CC 50 & 13,3 & 12,0 & 1,108 & 10,57 \\
CC 100 & 14,4 & 11,8 & 1,220 & 10,88 \\
CC 250 & 14,3 & 12,2 & 1,172 & 11,27 \\
CC 500 & 12,4 & 12,2 & 1,098 & 10,74 \\
CC 1000 & 11,4 & 12,0 & 0,950 & 9,27 \\
CC 2000 & 12,4 & 13,2 & 0,939 & 10,68 \\
SA 50 & 13,4 & 12,8 & 1,047 & 10,74 \\
SA 100 & 12,4 & 14,5 & 0,855 & 10,36 \\
SA 250 & 13,4 & 13,0 & 1,041 & 10,74 \\
SA 500 & 13,4 & 12,0 & 1,117 & 10,68 \\
SA 1000 & 12,4 & 12,5 & 0,992 & 10,36 \\
SA 2000 & 13,4 & 12,7 & 1,055 & 10,30 \\
CC $500+$ SA 500 & 13,4 & 11,7 & 1,145 & 10,46 \\
\hline
\end{tabular}

Aplicação de CCC $500 \mathrm{ppm}+\mathrm{SADH} 500 \mathrm{ppm}$ mostrou efeitos sensíveis de toxicidade na frutificação da 'Niagara Rosada'; sendo que de uma maneira geral os tratamentos com CCC mostraram não favorecer as características morfológicas das panículas da cultivar (quadros 3, 4, 6 e 7). Estes resultados não estão de acordo com aqueles obtidos por COOMBE (1965), BARRITT (1970) e PEREIRA \& YOSHIDA (1973) que estudaram outras cultivares de videira. COOMBE (1967) verificou uma diminuição no peso médio das bagas de cultivares com sementes pela aplicação de CCC; sendo que observou também que o CCC não afeta o comprimento da panícula, resultados esses de acordo com os obtidos no presente trabalho.

Aplicação de SADH $1000 \mathrm{ppm}$ diferiu significativamente da testemunha na primeira colheita, no que se refere ao peso da panícula, comprimento da panícula, peso das bagas e comprimento da ráquis (quadros 3 e 4). Estes resultados mostram-se semelhantes àqueles obtidos na colhei- 
ta final por TUKEY \& FLEMING (1968) com a cultivar 'Concord', diferindo daqueles conseguidos por BARRITT (1970).

Os tratamentos com SADH nas concentrações de 50 e 100 ppm parecem promover uma tendência de aumento no comprimento médio e largura média das bagas, sem contudo diferir significativamente do tratamento controle (quadros 3,4 e 6).

Pelos resultados obtidos no experimento, verifica-se que o tratamento com SADH $250 \mathrm{ppm}$ aplicado 5 dias antes do florescimento revelou-se bastante promissor na colheita final, diferindo significativamente do controle quanto ao peso da panícula, número de bagas, peso das bagas e número de sementes (quadros 6 e 7). COOMBE (1965) verificou aumento no peso da panícula devido a elevação do número de bagas com sementes por panícula pela aplicação de retardador de crescimento, portanto os incrementos no peso da panícula e das bagas verificados podem também estar relacionados com o aumento no número de sementes.

\section{CONCLUSÓES}

Do ensaio realizado chegou-se às seguintes conclusões:

1. Aplicação do cloreto de (2-cloroetil) trimetilamônio em pré-florescimento, nas concentrações utilizadas, não apresenta resultados favoráveis na frutificação da cultivar 'Niagara Rosada', nas condições de estudo.

2. SADH na concentração de $1000 \mathrm{ppm}$ provoca na primeira colheita aumento no peso e comprimento da panícula, peso das bagas e comprimento da ráquis.

3. A aplicação de $\mathrm{SADH}$ na concentração de $250 \mathrm{ppm}$ em pré-florescimento, promove aumento no peso e comprimento da panícula, número e peso das bagas, além de elevar o número de sementes.

\section{SUMMARY}

\section{EFFECTS OF GROWTH RETARDANTS ON FRUITING OF 'NIAGARA ROSADA' GRAPES}

Studies were carried out to establish the effects of exogenous growth regulators on Vitis (labrusca $x$ vinifera) 'Niagara Rosada' fruiting.

The investigations were done in the Jundiaí Research Station, Agronomic Institute State of São Paulo, always using disease-free vineyards of good productivity.

The morphological transformations of clusters were studied under the following aspects: weight, length and width of cluster; weight, length average and width average of berries; length average/width average 
ratio of berries; length and diameter of rachis; width of cluster minus berries; length and diameter of secondary rachis. The yield for the first half of the period from flowering to maturation was first determined. The same characteristics were determined at the time of maturity plus the number of berries, number of seeds, total sugars, total acid, Maturity Index and reducing sugars in samples of all treatments.

The experiment was conducted in order to determine the doses that resulted in the most beneficial effects, always using applications by immersion of the inflorescence.

In the experiment was realized applications of (2-chloroethyl) trimethylammonium chloride (CCC) and succinic acid-2, 2-dimethylhydrazide $(\mathrm{SADH})$ at concentrations of 50, 100, 250, 500, 1000 and $2000 \mathrm{ppm}$; CCC $500 \mathrm{ppm}$ plus SADH $500 \mathrm{ppm}$ and nontreated, 5 days before flowering, in 1971.

The concentrations of CCC applied before flowering did not affect favorably cluster morphology under the conditions of the experiment. Application of $\mathrm{SADH}$ at $250 \mathrm{ppm}$ before flowering increased the cluster weight and length, berries number and weight, and seed number. In the first yield treatment of $1000 \mathrm{ppm}$ of $\mathrm{SADH}$ increased the cluster weight and lenght, berry weight and rachis lenght.

\section{LITERATURA CITADA}

AUDUS, L. J. 1947 - Effects of certain organic metabolic products on plant nutrition and growth. Em: Int. Cong. Pure Appl. Chem. Rept. 11.

BARRITT, B. H. 1970 - Fruit set in seedless grapes treated with growth regulators Alar, CCC and gibberellin. J. Am. Soc. Hort. Sci. 95 : 58-61.

BENNET-CLARK, T. A. \& N. P. KEFFFORD 1953 - Chromatography of the growth substances in plant extracts. Nature $171: 645-647$.

BROWNE, C. A. \& F. W. ZERBAN 1941 - Physical and chemical methods of sugar analysis. John Wiley \& Sons Inc., New York. 1-1353.

COOMBE, B. G. 1965 - Increase in fruit set of Vitis vinifera by treatment with growth retardants. Nature $205: 305-306$.

COOMBE, B. G. 1967 - Effects of growth retardants on Vitis vinifera L. Vitis $6: 278-287$.

EL-ZEFTAWI, B. M. \& H. L. WESTE 1970 - Effects of some growth regulators on the fresh and dry yield of Zante currant (Vitis vinifera var.). Vitis 2:47-51.

FERRI, M. G., N. L. MENEZES \& W. R. M. SCANAVACCA 1969 - Glossário de têrmos botânicos. Editora Edgard Blucher Ltda., São Paulo 1-198.

FONT QUER, P. 1970 - Diccionario de botánica. Editorial Labor s. A., Barcelona 1-1244.

HARADA, H. \& A. LANG 1965 - Effect of some (2-chloroethyl) trimethylammonium chloride analogs and other growth retardants on gibberellin biosynthesis in Fusarium moniliforme. Plant Physiol. $40: 176-183$.

HEMBERG, T. 1949a - Significance of growth-inhibitory substances and auxins for the rest period of the potato tuber. Physiol. Plantarum $2: 24-36$. 
HEMBERG, T. 1949b - Growth-inhibitory substances in terminal buds of Fraxinus. Physiol. Plantarum $2: 37-44$.

KENDE, H., H. NINNEMANN \& A. LANG 1963 - Inhibition of gibberellic acid biosynthesis in Fusarium moniliforme by Amo-1618 and CCC. Naturwiss. 50 : 599-600.

KOCKEMANN, A. 1934 - Uber eine keimungshemmende Substance in fleischigen Fruchten. Ber. Deut. Bot. Ges. 52 : 523-526.

MULBORROW, B. V. 1967 - The identification of $(t)$ - abscisin II $((+)-$ dormin) in plants and measurement of its concentrations. Planita 76 : 93-113.

MITCHELL, J. W., J. W. WIRWILLE \& L. WEIL 1949 - Plant growth-regulating properties of some nicotinium compounds. Science $110: 252-254$.

NITSCH, J. P., C. PRATT, C. NITSCH \& N. J. SHAULIS 1960 - Natural growth substances in Concord and Concord Seedles grapes in relation to berry development. Am. J. Bot. 47 : 566-576.

PEREIRA, F. M. 1972 - Estudo da giberelina sobre a videira Niagara Rosada (Vitis labrusca $L$. $x$ Vitis vinifera L.). Tese de Doutoramento. E. S. A. «Luiz de Queiroz», Piracicaba 1-134.

PEREIRA, F. M. \& H. YOSHIDA 1973 - Respostas do cultivar de videira IAC 21-14 a.o fitohormônio Cycocel 500 A. Res. Congr. Bras. Frut., Minas Gerais 1.

PIMENTEL GOMES, F. 1963 - Cu.so de estatística experimental. Universidade de São Paulo. E. S. A. «Luiz de Queiroz», Piracicaba 1-384.

REED, D. J., T. C. MOORE \& J. D. ANDERSON 1965 - Plant growth retardant B-995: A possible mode of action. Science $148: 1469-1471$.

RIDDELL, J. A., H. A. HAGEMAN, C. M. J'ANTHONY \& W. L. HUBBARD 1962 - Retardation of plant growth by a new group of chemicals. Science $136: 391$.

RYUGO, K. \& R. M. SACHS 1969 - In vitro and in vivo studies of Alar (1,1-dimethylaminosuccinamic acid, B-995) and related substances. J. Am. Soc. Hort. Sci. 94 : 529-533.

SACHS, R. M., A. LANG, C. F. BRETZ \& J. ROACH 1960 - Shoot histogenesis: Subapical meristematic activity in a caulescent plant and the action of gibberellic acid and AMO-1618. Am. J. Bot. $47: 260-266$.

SOUSA, J. S. I. 1969 - Uvas para o Brasil. Edições Melhorameníos, São Paulo 1-454.

TOLBERT, N. E. 1960 - (2-chloroethyl) trimethylamonium chloride and related compounds as plant growth substances. J. Biol. Chem. $235: 475-479$.

TOLEDO, O. Z. 1960 - Instruções para a fabiricação do vinho. Inst. Agr. Est Campinas 121 : 1-68.

TUKEY, L. D. \& H. K. FLEMING 1967 - Alar, a new fruit-setting chemical for grapes. Pennsylvania Fruit News $46: 12-31$.

TUKKEY, L. D. \& H. K. FLEMING 1968 - Fruiting and vegetative effects of N-dimethylaminosucciramic acid on 'Concord' grapes, Vitis labrusca L. Proc. Am. Soc. Hort. Sci. 93 : 300-310.

TUKEY, L. D. \& H. K. FLEMING 1970 - Post-year effects of N-dimethylaminosuccinamic acid on 'Concord' grapes, Vitis labrusca L. HortScience 5 : 161-163.

VALADARES, J., I. F. LEPSCH \& A. KUPPER 1971 - Levantamento pedológico detalhado da Estação Experimental de Jundiaí, S. P. Bragantia 30(25):337-386.

WEAVER, R. J. 1972 - Plant growth substances in agriculture. W. H. Freeman and Companhy, San Francisco 1.594.

WIRWILLE, J. W. \& J. W. MITCHELL 1950 - Six new plant growth inhibiting compounds as plant growth substances. J. Biol. Chem. $235: 475-479$. 
